Katja Dengel

\title{
Die europäische Vereinheitlichung des Internationalen Ehegüterrechts und des Internationalen Güterrechts für eingetragene Partnerschaften
}

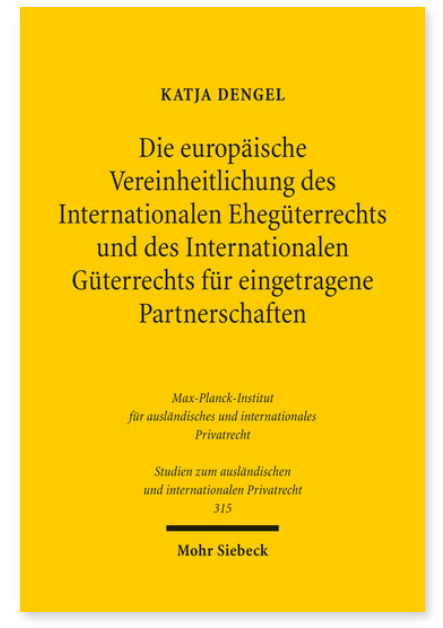

2014. XXXIII, 414 Seiten. StudIPR 315

ISBN 978-3-16-153478-2

DOI 10.1628/978-3-16-153478-2

eBook PDF 104,00€

ISBN 978-3-16-153457-7

fadengeheftete Broschur 104,00€
Die Kommissionsvorschläge zum Internationalen Ehegüterrecht und zum Internationalen Güterrecht für eingetragene Partnerschaften sollen einen klaren Rechtsrahmen für grenzüberschreitende vermögensrechtliche Wirkungen einer Ehe bzw. eingetragenen Partnerschaft schaffen. Katja Dengel analysiert die vorgeschlagenen Texte auf der Basis eines Vergleichs aller mitgliedstaatlichen Sach- und Kollisionsrechte. Schwerpunkte sind der Anwendungsbereich, die objektiven und subjektiven Anknüpfungsmomente sowie ausgewählte Fragen des Allgemeinen Teils. Der Vorschlag zur Vereinheitlichung des Internationalen Güterrechts für eingetragene Partnerschaften wird darüber hinaus unter dem Gesichtspunkt einer möglichen Diskriminierung gleichgeschlechtlicher Paare beleuchtet. Die Arbeit mündet in konkrete Verbesserungsvorschläge.

Katja Dengel Geboren 1981; Studium der Rechtswissenschaften und Begleitstudium 'Europäisches Recht' an der JuliusMaximilians- Universität Würzburg; Referendariat in Würzburg; wissenschaftliche Mitarbeiterin in Würzburg; 2014 Promotion.
Jetzt bestellen:

https://mohrsiebeck.com/buch/die-europaeische-vereinheitlichung-des-internationalen-ehegueterrechts-und-desinternationalen-gueterrechts-fuer-eingetragene-partnerschaften-9783161534782?no_cache=1

order@mohrsiebeck.com

Telefon: +49 (0)7071-923-17

Telefax: $+49(0) 7071-51104$ 